\title{
Design of Robust Power System Stabilizer For SMIB System Using Nevanlinna-Pick theory
}

\author{
Anshul Shekhar, Rekha \\ Deptt.of Electrical Engg. NIT Jamshedpur (Jharkhand), India
}

\begin{abstract}
The main aim of this paper is to damp out power system oscillations, which has been recognized as one of the major concerns in power system operation. This paper proposes a robust controller design for single machine infinite bus system based on Modified Nevanlinna-Pick theory along with Heffron-Phillip's K model to stabilize power systems with unstable or lightly damped rotor modes. Most of the methods are not only complex but also require apriority knowledge of the complete system data. The method as proposed for single machine infinite bus system is easy to implement and gives better performance over wide range of operating conditions as compare to conventional one.
\end{abstract}

Keywords: Modified Nevanlinna-Pick theory (MNP), Heffron-Phillip's model(HP) ,Power System Stabilizers (PSS), Single Machine connected Infinite Bus (SMIB).

\section{Introduction}

Modern power systems are interconnected non-linear time varying systems. Stable operation of such a complex system at a given operating equilibrium, sustaining large variety of small and large disturbances depends upon variety of controllers. In spite of the availability of high gain fast excitation controllers, the small signal oscillatory instability or low frequency oscillation remains a major concern in power system operation. In multi-machine systems this is manifested as multi-modal oscillations, which once excited can persist for long period of time and in some cases can cause generators to pull out of synchronism. This thesis is concerned with the design of power system stabilizer to contain these oscillations. The major factors contributing to the oscillatory instability were found to be dependent upon [5]

1. The loading of the generator tie line.

2. Power transfer capability of transmission line.

3. Power factor of the generator (leading power factor operation is more problematic than Lagging power factor operation).

4. The gain and time constant of the AVR.

In interconnected power systems, three different modes of oscillation can be detected [6].

1. Intra-plant modes in which only the generators in a power plant participate. The oscillation frequencies are generally high in the range of 1.5 to $3.0 \mathrm{~Hz}$.

2. Local modes in which several generators in an area participate. The frequencies of oscillations are in the range of 0.8 to $1.8 \mathrm{~Hz}$.

3. Inter area modes in which generators over an extensive area participate. The oscillation frequencies are low and in the range of 0.1 to $0.8 \mathrm{~Hz}$.

\section{Power System Stabilizer}

The most cost effective way of countering small-signal oscillatory instability is to use auxiliary controllers called power system stabilizers (PSS) to produce additional damping in the system [5]. Real power systems are nonlinear dynamic systems and as the operating condition changes, so does the system dynamics [4]. A well designed damping controller should ensure that the oscillations are well damped under all operating conditions. Designing an effective PSS for all operating conditions still remains a difficult task due to the following reasons:

1. Large variations in operating conditions.

2. Large variety of disturbances that can occur in power systems during normal operation.

3. Variation in system parameters due to changes in network configuration.

4. Difficulty in working out mathematical models capable of adequately modelling the Generator under various operating conditions.

There are different types of controller each having some advantages and disadvantages [7].

- Conventional Fixed Parameters Controllers

- Adaptive Controllers

- Fuzzy Logic Controllers 
- Application of Genetic Algorithm

- Robust Control

Robust systems are less sensitive to changes in operating conditions and provide adequate damping over a wide operating range.

\section{The Modified Nevanlinna-Pick Theory}

To overcome the disadvantages of classical NP theory a Modified Nevanlinna-Pick theory are described below. The general procedure is as follows:

1. A solution to interpolation problem with BR function $\mathrm{u}(\mathrm{s})$ exists if and only if the Youla indices associated with pi are positive when aiis complex, or $\left|p_{i}\right| \leq 1$ when $a_{i}$ is real. Where bounded real (BR) function $u(s)$ satisfies.

$$
u_{j}\left(a_{i}\right)=p_{i} \quad j=n, n-1, \ldots, 1
$$

As $a_{i}$ is complex it allows us to apply the Nevanlinna-Pick (NP) algorithm for the rotor poles lying in left or right half of s- plane.

2. Select an arbitrary BR function $\mathrm{u}_{\mathrm{j}+1}(\mathrm{~s})$ and use the interpolation formula compute $\mathrm{uj}(\mathrm{s})$.

$$
\mathrm{u}_{\mathrm{j}}(\mathrm{s})=\frac{u j+1(s)_{\lambda j}(s)+\mu j(s)}{\mu j+1(s)_{\gamma j}(s)+1} \quad \mathrm{j}=\mathrm{n}, \mathrm{n}-1, \ldots, 1
$$

$\lambda \mathrm{j}(\mathrm{s}), \mu \mathrm{j}(\mathrm{s})$ and $\square \mathrm{j}(\mathrm{s})$ are some functions which depend on $\mathrm{a}_{\mathrm{i}}$ and $\mathrm{p}_{\mathrm{i}}$.

The function $\mathrm{u}_{\mathrm{j}+1}(\mathrm{~s})$ is an arbitrary BR function. Therefore the solution is not unique. The NP theory is solvable if the so called Youla indices are positive. This condition limits the choice of $p_{i}$ and consequently the plant perturbation $r_{m}\left(a_{i}\right)$ defined above. The Youla indices for a given interpolation point $\square_{i}$ in $(4.14)$ and ai $=\sigma i+j \omega_{i}$ are given by eq. (3.3) below

$$
\begin{array}{ll}
I_{1}\left(a_{i}\right)=\frac{R_{i} / \sigma_{i}-X_{i} / \omega_{i}}{R_{i} / \sigma_{i}+X_{i} / \omega_{i}}, & I_{2}\left(a_{i}\right)=\frac{2\left|\frac{1+\rho_{i}}{1-\rho_{i}}\right|^{2}}{R_{i} / \sigma_{i}+X_{i} / \omega_{i}}, \\
I_{3}\left(a_{i}\right)=\frac{2}{R_{i} / \sigma_{i}-X_{i} / \omega_{i}}, & I_{4}=I_{1}^{-1} . \\
\text { where } \quad R_{i}=\frac{1-\left|\rho_{i}\right|^{2}}{\left|1-\rho_{i}\right|^{2}}, & X_{i}=\frac{23 \rho_{i}}{\left|1-\rho_{i}\right|^{2}} \mid
\end{array}
$$

\section{Applying the Modified Nevanlinna-Pick theory to Robust Stability}

The procedure for the controller design is as follows[4]:

1. Define a function $D(s)$ having magnitude less than or equal to unity for all values of $s=j \omega$ as

$$
D(s)=\frac{(s-a 1) \ldots \ldots \ldots \ldots . .(s-a n)}{(s-a 11) \ldots \ldots \ldots . .(s-a 1 n)}
$$

Where $a_{1}, \ldots \ldots . a_{n}$ are the unstable/lightly damped poles of the nominal system anda $a_{11, \ldots \ldots \ldots . . . .} a_{1 n}$ are the corresponding desired poles of the system with robust controller.

2. Define a stable proper transfer function as

$$
\hat{\mathrm{P}}_{\mathrm{n}}(\mathrm{s})=\mathrm{P}_{\mathrm{n}}(\mathrm{s}) \mathrm{D}(\mathrm{s})
$$

3. Initialize $\mathrm{r}_{\mathrm{m}}\left(\mathrm{a}_{\mathrm{i}}\right)$ the plant perturbation to zero.

4. Increase the value of $r_{m}\left(a_{i}\right)$ from the previous assign value in small steps for each iteration.

5. For each iterative value of $r_{m}\left(a_{i}\right)$ compute $\square_{i}$ as follows.

$$
p i=\frac{\mathrm{rm}(\mathrm{ai})}{p n(a i)} \quad \mathrm{i}=1, \ldots \ldots \ldots \ldots . . \mathrm{n}
$$

6. Having $\square_{\mathrm{i}}$ and $\mathrm{r}_{\mathrm{m}}\left(\mathrm{a}_{\mathrm{i}}\right)$ for each iteration, calculate the Youla Indices from [1]. Repeat steps 4, 5 , and 6 till the maximum value of $r_{m}\left(a_{i}\right)$ is found, for which the positiveness of Youla Indices is ensured then go to step 7.

7. From [1] compute solution $\mathrm{u}_{\mathrm{j}}(\mathrm{s})$ (bounded real function) of NP theory in terms of an arbitrary (free) BR function $\mathrm{u}_{\mathrm{j}+1}(\mathrm{~s})$.

8. Using $\mathrm{Q}(\mathrm{s})=\mathrm{Q}(\mathrm{s}) \overline{\mathrm{D}}(\mathrm{s})$ in the relation $\mathrm{Q}(\mathrm{s})=\mathrm{u} \overline{(\mathrm{s})} / \mathrm{r}_{\mathrm{m}}\left(\mathrm{a}_{\mathrm{i}}\right)$. We can get $\mathrm{Q}(\mathrm{s})$ as:

$$
Q(s)=\frac{D(d)}{r m(a i)} u(s)
$$

9. The robust controller transfer function $\mathrm{C}(\mathrm{s})$ is obtained from equation (4.4).

$$
\mathrm{C}(\mathrm{s})=\mathrm{Q}(\mathrm{s})(1-\operatorname{Pn}(\mathrm{s}) \mathrm{Q}(\mathrm{s}))
$$




\section{Modelling Of Power System}

This Single Machine Infinite Bus (SMIB) power system model [2] is used to obtain the linearized dynamic model (Heffron-Phillip's or K-constant model). Basic equations related with SMIB system are written below.

$$
\begin{aligned}
& \frac{d}{d t} \delta=\omega_{\mathrm{b}} \mathrm{S}_{\mathrm{m}} \\
& \frac{d}{d t} \mathrm{~S}_{\mathrm{m}}=[-\mathrm{DSm}+\text { Tmech-Telec }] / 2 \mathrm{H} \\
& \frac{d}{d t} \mathrm{E}_{\mathrm{d}}^{\prime}=\left[-\mathrm{E}_{\mathrm{d}^{-}}^{\prime}\left(\mathrm{X}_{\mathrm{q}}-\mathrm{X}_{\mathrm{q}}^{\prime}\right) \mathrm{i}_{\mathrm{q}}\right] / \mathrm{T}_{\mathrm{q}}^{\prime}{ }_{\mathrm{o}} \\
& \frac{d}{d t} \mathrm{E}_{\mathrm{fd}}=\frac{\left[\mathrm{K}_{\mathrm{A}}\left(\mathrm{V}_{\mathrm{ref}}+\mathrm{V}_{\mathrm{s}}-\mathrm{V}_{\mathrm{t}}\right)-\mathrm{E}_{\mathrm{fd}}\right]}{\mathrm{T}_{\mathrm{A}}} \\
& T_{\text {elec }}=E_{d d_{d}}^{\prime} i_{d}+E_{q}^{\prime} i_{q}+\left(X_{d^{-}}^{\prime} X_{q}^{\prime}\right) i_{d_{1}} i_{q} \\
& S_{\mathrm{m}}=\frac{\omega-\omega_{\mathrm{b}}}{\omega_{\mathrm{b}}}
\end{aligned}
$$

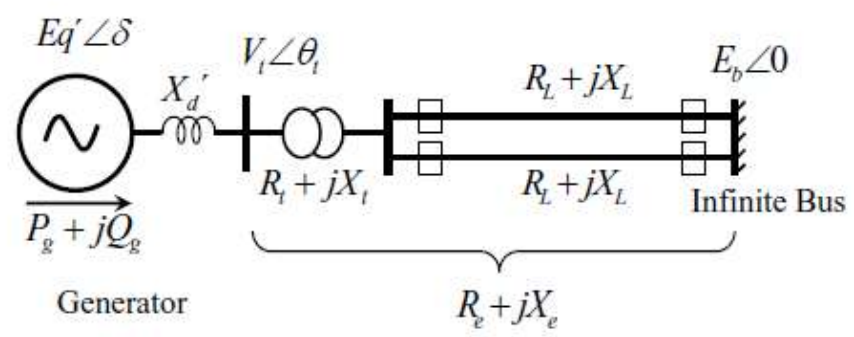

Fig.1: A single machine infinite-bus system

Linearized equations can be written as,

$$
\begin{aligned}
& \Delta \delta^{1}=\omega_{\mathrm{b}} \Delta \mathrm{S}_{\mathrm{m}}
\end{aligned}
$$

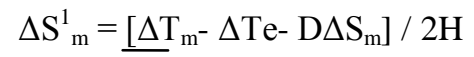

$$
\begin{aligned}
& \Delta \mathrm{T}_{\mathrm{e}}=\mathrm{K}_{1} \Delta \delta+\mathrm{K}_{2} \Delta \mathrm{E}_{\mathrm{q}}^{\prime}
\end{aligned}
$$

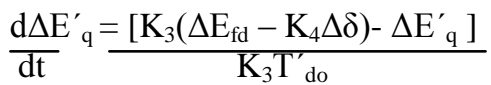

$$
\begin{aligned}
& \Delta \mathrm{V}_{\mathrm{t}}=\mathrm{K}_{5} \Delta \delta+\mathrm{K}_{6} \Delta \mathrm{E}^{\prime} \mathrm{q} \\
& \frac{\mathrm{d} \Delta \mathrm{E}_{\mathrm{fd}}^{\prime}}{\mathrm{dt}}=\frac{\left[\mathrm{K}_{\mathrm{A}}\left(\Delta \mathrm{V}_{\mathrm{ref}}+\Delta \mathrm{V}_{\mathrm{pss}}-\Delta \mathrm{V}_{\mathrm{t}}\right)-\Delta \mathrm{E}_{\mathrm{fd}}^{\prime}\right]}{\mathrm{T}_{\mathrm{A}}}
\end{aligned}
$$

Heffron-Phillip's constants K1 ,K6 are defined as below.

$$
\begin{array}{ll}
K 1=\frac{E b E q o \cos \delta o}{X q+X e}+\frac{X q-X^{\prime} d}{X e+X^{\prime} d} \mathrm{E}_{\mathrm{b}} \sin \delta o & \mathrm{~K}_{2}=\frac{X q+X e}{X e+X^{\prime} d} i q o \\
\mathrm{~K}_{3}=\frac{X e+X^{\prime} d}{X d+X e} & \mathrm{~K}_{4}=\frac{X d-X^{\prime} d}{X e+X^{\prime} d} E b \sin \delta o \\
\mathrm{~K}_{5}=-\frac{X q V d o E b \cos \delta o}{(X q+X e) V t o}-\frac{X^{\prime} d V q o \sin \delta o}{\left(X e+X^{\prime} d\right) V t o} & \mathrm{~K}_{6}=\frac{X e}{X e+X^{\prime} d} \frac{V q o}{V t o}
\end{array}
$$

Where $\mathrm{E}_{\mathrm{qo}}=\mathrm{E}_{\mathrm{qo}}^{\prime}-\left(\mathrm{X}_{\mathrm{q}}-\mathrm{X}_{\mathrm{d}}^{\prime}\right) \mathrm{i}_{\mathrm{do}}$

$\delta_{0} ; \mathrm{S}_{\mathrm{m} 0} ; \mathrm{E}_{\mathrm{q} 0}^{\prime} ; \mathrm{E}_{\mathrm{fd} 0}$ and $\mathrm{V}_{\mathrm{t} 0}$ denote the values at the initial operating condition. 


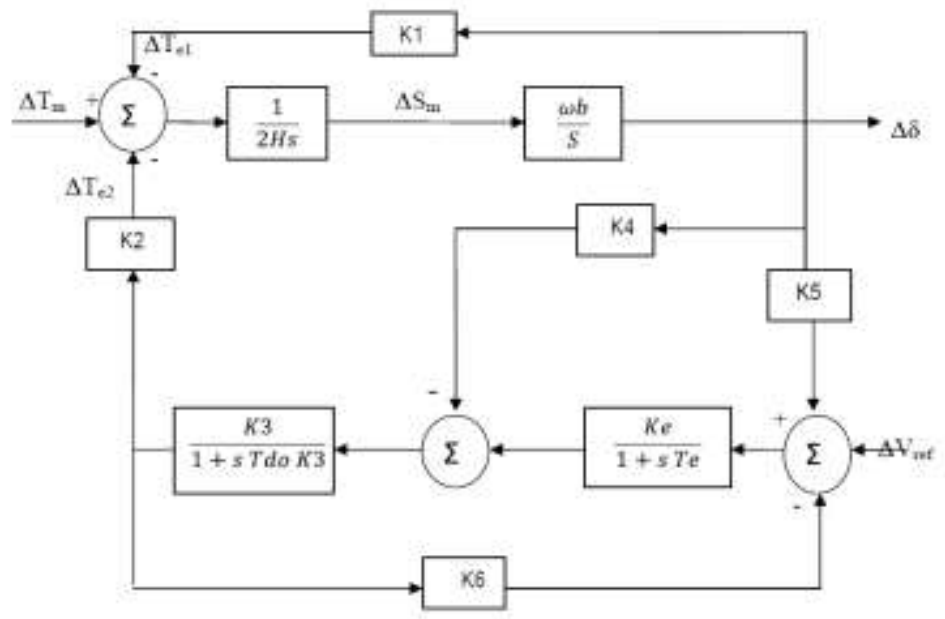

Fig. 2: Heffron-Phillip's or K-constant model for SMIB system based on [3]

\subsection{State Equation of Small Signal Model:}

Linearized state-space form of the above system is given below.

$$
\square=[\mathrm{A}] \mathrm{X}+[\mathrm{B}] \Delta \mathrm{Vref}
$$

Where, $\mathrm{X}=\left[\Delta \delta ; \Delta \mathrm{S}_{\mathrm{m}} ; \Delta \mathrm{E}^{\prime} \mathrm{q} ; \Delta \mathrm{E}_{\mathrm{fd}}\right]$

The matrices $\mathrm{A}$ and $\mathrm{B}$ can be obtained as

$$
A=\left[\begin{array}{cccc}
0 & \omega_{B} & 0 & 0 \\
-\frac{K_{1}}{2 H} & -\frac{D}{2 H} & -\frac{K_{2}}{2 H} & 0 \\
-\frac{K_{4}}{T_{d R_{5}}^{\prime}} & 0 & -\frac{1}{K_{3} T_{d o}^{\prime}} & \frac{1}{T_{d q}^{\prime}} \\
-\frac{K_{A} K_{5}}{T_{A}} & 0 & -\frac{K_{A} K_{6}}{T_{A}} & -\frac{1}{T_{A}}
\end{array}\right] ; B=\left[\begin{array}{c}
0 \\
0 \\
0 \\
\frac{K_{A}}{T_{A}}
\end{array}\right] ;
$$

The small signal stability of the system can be improved by applying an auxiliary signal, derived from the deviation in speed signal $\Delta \omega$ at the voltage reference input of the excitation system. The system transfer function, $\mathrm{P}(\mathrm{s})=\Delta \omega / \Delta$ Vref in terms of K-parameters, can be found by using fourth-order linearized model as shown in Fig.2.

$$
\begin{aligned}
& \operatorname{Pn}(\mathrm{s})=-\mathrm{K}_{\mathrm{A}} \mathrm{K}_{2} \mathrm{~K}_{3} \mathrm{~S} / \mathrm{M}(\mathrm{S}) \\
& \text { where } \quad M(s)=2 H T_{d o}^{\prime} K_{3} T_{A} s^{4}+\left(2 H T_{d o}^{\prime} K_{3}+D T_{d o}^{\prime} K_{3} T_{A}+2 H T_{A}\right) s^{3}+\left(\omega_{b} K_{1} K_{3} T_{A} T_{d o}^{\prime}+\right. \\
& \left.2 H K_{3} K_{2} K_{A}+D T_{d o}^{\prime} K_{3}+D T_{A}+2 H\right) s^{2}+\left(-\omega_{b} K_{2} K_{3} K_{4} T_{A}+\omega_{b} K_{1} K_{3} T_{d o}^{\prime}+D K_{3} K_{6} K_{A}+\right. \\
& \left.\omega_{b} K_{1} T_{A}+D\right) s-\omega_{b} K_{2} K_{3} K_{5} K_{A}+\omega_{b} K_{1} K_{3} K_{6} K_{A}-\omega_{b} K_{2} K_{3} K_{4}+\omega_{b} K_{1}
\end{aligned}
$$

\section{Power System Stabilizer Design}

The theory developed in the preceding section is applied in this section for the design of power system stabilizers for nominal SMIB power system $(\mathrm{S}=\mathrm{P}+\mathrm{jQ}=0.4+\mathrm{j} 0.084$ p.u. $\mathrm{Xe}=0.37 \mathrm{p} . \mathrm{u})$ [8]. At this operating condition the Heffron-Phillip's constants for the nominal plant whose system parameter are given in Appendix are computed as, $\mathrm{K}_{1}=1.0, \mathrm{~K}_{2}=0.362, \mathrm{~K}_{3}=0.46, \mathrm{~K}_{4}=0.437, \mathrm{~K}_{5}=-0.093$ and $\mathrm{K}_{6}=0.350$. Using (5.15) the linearized fourth order transfer function of SMIB power system is obtained:

$$
\operatorname{Pn}(\mathrm{s})=\frac{-43.73 \mathrm{~s}}{(\mathrm{~s} 4+34.27 \mathrm{~s} 3+409 \mathrm{~s} 2+1537.1 \mathrm{~s}+14927.7)}
$$

The lightly damped mechanical modes of the above characteristic equation are $\mathrm{a}_{1}=-0.16+6.47 \mathrm{i} ; \mathrm{a}_{2}=-0.16-$ $6.47 \mathrm{i}$.

The maximum allowable perturbation with which the system stability is guaranteed is dependent upon pole placement. The allowable perturbation for various pole placement of the plant is listed in Table 1.1. It can be seen that choosing a smaller damping ratio results in larger allowable perturbation for the same plant. 
Controllers $\mathrm{C}_{1}(\mathrm{~s})$ to $\mathrm{C}_{5}(\mathrm{~s})$ have been designed for all the desired pole location listed in Table 1.1 by the proposed method. . Fig. 3 shows the response of the plant following a 0.1 pu step change of $V_{\text {ref }}$ for each of the five controllers. The plant response is highly oscillatory without a damping controller. A well designed conventional PSS tuned for this operating condition is able to damp the oscillations fairly well.

Table 1.1: Plant perturbation $\left(\mathrm{r}_{\mathrm{m}}\left(\mathrm{a}_{1}\right)\right)$ for SMIB system with varying Damping Ratio

\begin{tabular}{|c|c|c|c|}
\hline Controller & Desired Poles & Damping Ratio $(\varsigma)$ & Perturbation rm(a1) \\
\hline $\mathbf{C}_{\mathbf{1}}$ & $-1.15 \pm 6.47 \mathrm{i}$ & 0.175 & 0.0592 \\
\hline $\mathbf{C}_{\mathbf{2}}$ & $-2 \pm 6.47 \mathrm{i}$ & 0.295 & 0.0316 \\
\hline $\mathbf{C}_{\mathbf{3}}$ & $-3 \pm 6.47 \mathrm{i}$ & 0.421 & 0.0202 \\
\hline $\mathbf{C}_{\mathbf{4}}$ & $-4 \pm 6.47 \mathrm{i}$ & 0.526 & 0.0147 \\
\hline $\mathbf{C}_{\mathbf{5}}$ & $-5 \pm 6.47 \mathrm{i}$ & 0.611 & 0.0113 \\
\hline
\end{tabular}

Step 1: Evaluate function $D(s)$ defined in (4.1) for desired poles $\left(a_{11}, a_{12}\right)$ at $-5 \pm 6.47$.

$$
\mathrm{D}(\mathrm{s})=\frac{(\mathrm{s}-0.16 \pm 6.47 \mathrm{i})}{(\mathrm{s}+5 \pm 6: 47 \mathrm{i})}
$$

Which satisfies the criteria $|\mathrm{D}(\mathrm{j} \omega)| \leq 1 \forall \omega$

Step 2: A stable proper transfer is derived from (4.2)

$$
\mathrm{P}_{\mathrm{n}}(\mathrm{s})=\frac{-43.73 \mathrm{~s}}{(\mathrm{~s} 4+43.95 \mathrm{~s} 3+762.64 \mathrm{~s} 2+5833 \mathrm{~s}+23824.4)}
$$

Step 3: following the steps ( 3 to 6 ) in the section IV of this paper. The maximum plant perturbation $\mathrm{r}_{\mathrm{m}}\left(\mathrm{a}_{1}\right)$ is found to be 0.0113 till the Youla indices becomes positive.

Step 4: Replacing proper transfer $\sim \operatorname{Pn}(\mathrm{s})$ function and plant perturbation $\mathrm{r}_{\mathrm{m}}\left(\mathrm{a}_{1}\right)=0.0113$ in (4.3), the value of plant interpolation $\rho_{1}=-0: 982+0: 231 \mathrm{i}$ and $\rho_{2}=-0: 982-0: 231 \mathrm{i}$.

Table 2.2: Youla Indices and Pick matrix

\begin{tabular}{|l|l|l|c|}
\hline & Youla Indices & & Pick Matrix \\
\hline $\mathrm{I}_{1}$ & 4.686 & $\mathrm{P}_{11}$ & 0.055 \\
\hline $\mathrm{I}_{2}$ & 2.772 & $\mathrm{P}_{12}$ & $-0.0352-0.006 \mathrm{i}$ \\
\hline $\mathrm{I}_{3}$ & 43.86 & $\mathrm{P}_{21}$ & $-0.0352+0.006 \mathrm{i}$ \\
\hline $\mathrm{I}_{4}$ & 0.213 & $\mathrm{P}_{22}$ & 0.055 \\
\hline & & $\mathrm{P}$ & 0.0017 \\
\hline
\end{tabular}

Step 5: The value of Pick matrix and Youla indices as given in Table 1.2 can be derived by eq.3.3

Step 6: Now the solution of the NP theory can be found in terms of the arbitrary BR function $\mathrm{u}_{\mathrm{j}+1}(\mathrm{~s})$. In this case the function is $\mathrm{u}(\mathrm{s})$ because generator has only one pair of lightly damped poles under nominal operating condition. Selecting $\mathrm{u}_{2}(\mathrm{~s})=0$ the PSS transfer function acts as a controller as well as a washout. Replacing $\mathrm{u}_{2}(\mathrm{~s})$ $=0$ in (3.2) the solution of NP theory is

$$
\mathrm{u}(\mathrm{s})=\frac{0 . \lambda 1(\mathrm{~s})+\mu 1(\mathrm{~s})}{0 . \gamma 1(\mathrm{~s})+1}=\frac{(\mathrm{I} 4-\mathrm{I} 1) \mathrm{s} 2+(\mathrm{I} 2-\mathrm{I} 3) \mathrm{s}}{(\mathrm{I} 4+\mathrm{I} 1) \mathrm{s} 2+(\mathrm{I} 2+\mathrm{I} 3) \mathrm{s}+2|\mathrm{a} 1| 2}=\frac{-0.91 \mathrm{~s} 2-8.39 \mathrm{~s}}{\mathrm{~s} 2+9.52 \mathrm{~s}+17.11}
$$

where values of $\mathrm{I}_{1}, \mathrm{I}_{2}, \mathrm{I}_{3}$ and $\mathrm{I}_{4}$ are given in Table 2.2

Step 7: Replacing $\mathrm{u}(\mathrm{s})$ in (4.4) and (4.5) we can get the controller transfer function as:

$$
\mathrm{C}_{5}(\mathrm{~s})=-80.79 \frac{\mathrm{s}(\mathrm{s}+9.19)(\mathrm{s} 2+33.95 \mathrm{~s}+356.24)}{(\mathrm{s}+1.62)(\mathrm{s}+8.87)(\mathrm{s} 2+42.66 \mathrm{~s}+677.16)}
$$

With this controller transfer function there is need for a separate washout circuit, since with no system oscillations the output of the controller is zero. $\mathrm{C}_{1}(\mathrm{~s})$ to $\mathrm{C}_{4}(\mathrm{~s})$ are 


$$
\begin{aligned}
& C_{1}(s)=-16.5 \frac{s^{4}+34.67 s^{3}+380.5 s^{2}+255 s}{s^{4}+39.66 s^{3}+566.3 s^{2}+1780 s+3067} \\
& C_{2}(s)=-30.4 \frac{s^{4}+36.2 s^{3}+433 s^{2}+805 s}{s^{4}+42.3 s^{3}+607.5 s^{2}+2612 s+4572.3} \\
& C_{3}(s)=-44.4 \frac{s^{4}+39.44 s^{3}+542.7 s^{2}+1956.3 s}{s^{4}+46.34 s^{3}+840.4 s^{2}+4547 s+8012} \\
& C_{4}(s)=-49.3 \frac{s^{4}+45.4 s^{3}+746.1 s^{2}+4091 s}{s^{4}+51 s^{3}+1048.6 s^{2}+7806 s+14187}
\end{aligned}
$$

\section{Observation And Result}

With the proposed PSS design the damping is least with controller $\mathrm{C}_{1}(\mathrm{~s})$ and maximum with controller $\mathrm{C}_{5}(\mathrm{~s})$. However, the maximum allowable plant perturbation which could be due to unmodelled dynamics or changes in plant operating parameters, is maximum with controller $\mathrm{C}_{1}(\mathrm{~s})$ and minimum with controller $\mathrm{C}_{5}(\mathrm{~s})$. At lower damping (desired poles at $-1.15 \pm 6.47 \mathrm{i}$ and $-2 \pm 6.47 \mathrm{i}$ ) the performance of the conventional stabilizer is better. At desired pole location of $-3 \pm 6.47 \mathrm{i}$ the performance of the controllers are comparable. At higher damping the performance of the propose controller is better.
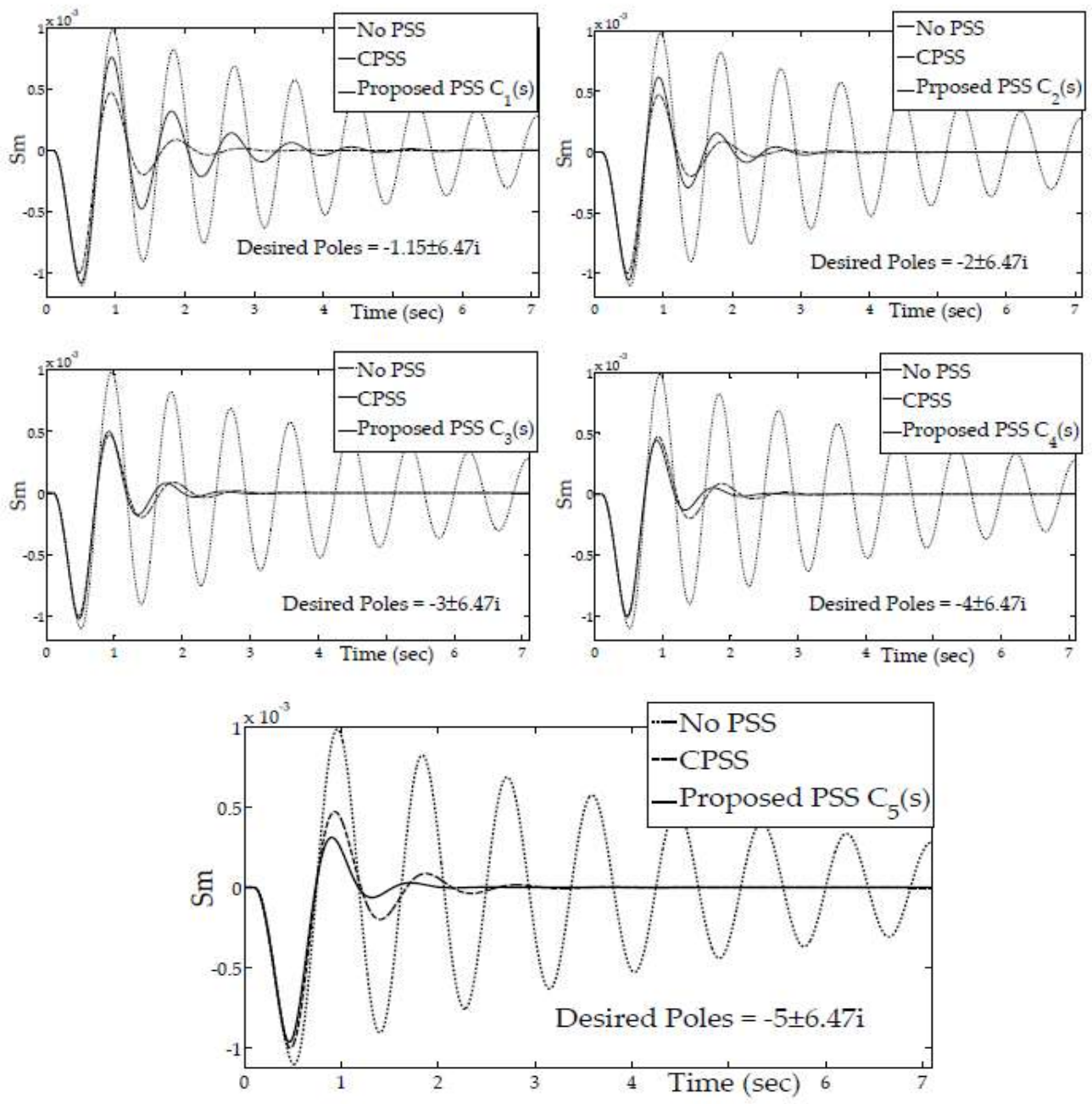

Fig 3: System response in terms of slip $S_{m}$ for increase in $V_{\text {ref }}$ by $0.1 \mathrm{pu}$

\section{Conclusion}

The Proposed PSS is physically realizable with real coefficients. In the proposed controller design, unlike in the conventional PSS design, there is no need for the computation of appropriate gain and time constants of the stabilizer. The performance of the proposed robust stabilizer is consistently better than that of a conventional PSS under all operating and system conditions for different types of disturbances. 
The greatest advantage of the proposed stabilizer is that there is no need for tuning of stabilizers constants. On the other hand, the design of conventional PSS requires considerable expertise and experience for the selection and tuning of PSS and washout circuit parameters. The proposed stabilizer design based on modified NP theory has the added advantage that the close loop system performance is an integral part of design process. The controller also guarantees system stability so long the plant uncertainty is limited to the uncertainty bound function. The uncertainty is however unstructured and includes variation in plant parameters and modelling errors within limits. The uncertainty bound within which the proposed PSS is effective depends upon the choice of the nominal plant for PSS design.

This system data is taken from [8]

\section{Appendix}

\section{Machine Data:}

$\mathrm{Xd}=1.863, \mathrm{X}^{\prime} \mathrm{d}=0.657, \mathrm{~T}^{\prime} \mathrm{do}=6.9, \mathrm{H}=4, \mathrm{D}=5, \mathrm{fB}=50 \mathrm{~Hz}$,

$\mathrm{EB}=1 \mathrm{p} . \mathrm{u}, \mathrm{Vt}=1.02 \mathrm{p} . \mathrm{u}, \mathrm{Xt}=0.127 \mathrm{p} . \mathrm{u}, \mathrm{Xe}=0.36965$

\section{Static Excitation System Data:}

$\mathrm{Ke}=200, \mathrm{Te}=0: 03 \mathrm{~s}$,Efdmax $=6$, Efdmin $=-6$.

\section{PSS Data:}

$\mathrm{T} 1=0.2, \mathrm{~T} 2=0.05, \mathrm{Kpss}=20 ; \mathrm{Tw}=3 ;$ PSS output limits $= \pm 0.1$

\section{References}

[1] G. Sai Sudheer, B N S P Venkatesh, Emandi. Ramesh, Doradla. Prathap Hari Krishna,’Design Of Power System Stabilizer To Improve Small Signal Stability By Using Modified Heffron-Phillip's Model” IJEST, Vol. 3 No. 6, pp. 4888-4896, June 2011.

[2] P. Dorato, Yunzhi Li, "A Modification of the Classical Nevanlinna-Pick Interpolation Algorithm with Application to Robust Stabilization", IEEE Trans. Vol. AC-31, pp. 645-648, , July 1986.

[3] P.S. Kundur, Power System Stability and Control. New York: McGraw-Hill, Inc.,1994.

[4] K. R. Padiyar, POWER SYSTEM DYNAMICS Stability and Control. John Wiley; Interline Publishing, 1996.

[5] P.S. Rao,"On The Design of Robust Power System Damping Controllers", Ph.D Thesis, Indian Institute of Science, Bangalore , May 1998.

[6] G. Gurrala and I. Sen, “A Modified Heffron-Phillip's Model for The Design of Power System Stabilizers," in POWERCON 2008, New Delhi, India, October 12 - 15, 2008.

[7] P. Kundur, M. Klein, G. J. Rogers, M. S. Zywno, "Application of Power System Stabilizer for Enhancement of Overall System Stability", IEEE Trans. Vol. PWRS-4, pp. 614-626, May 1989.

[8] C.Zhu, R.Zhou, and Y. Wang, "A new nonlinear voltage controller for power systems,"Int. J. Electr. Power and Energy Syst., vol. 19, pp. 19-27, 1997.

[9] F. P. de Mello, C. Concordia, "Concept of Synchronous Machine Stability as Affected by Excitation Control", IEEE Trans. Vol. PAS-88, pp. 316-329, April 1969. 